\title{
Role of noncoding RNAs in cholangiocarcinoma (Review)
}

\author{
YINGHAO LV $^{1 *}$, ZHENZHEN WANG ${ }^{2}, \mathrm{KUN}^{*} \mathrm{ZHAO}^{1}$, \\ GUOKUN ZHANG $^{1}$, SHUAI HUANG ${ }^{1}$ and YONGFU ZHAO ${ }^{1 *}$
}

Departments of ${ }^{1}$ Hepatobiliary and Pancreatic Surgery, and ${ }^{2}$ Pediatric Surgery, The First Affiliated Hospital of Zhengzhou University, Zhengzhou, Henan 476100, P.R. China

Received November 28, 2019; Accepted March 16, 2020

DOI: 10.3892/ijo.2020.5047

\begin{abstract}
Cholangiocarcinoma (CCA) is a malignant tumour originating from biliary epithelial cells, and is increasing in incidence. Radical surgery is the main treatment. However, the pathogenesis of CCA is unclear. Noncoding RNAs (ncRNAs) are non-protein-coding RNAs produced by genomic transcription that include microRNAs (miRNAs), circular RNAs (circRNAs) and long noncoding RNAs (lncRNAs). They play important roles in gene expression, epigenetic modification, cell proliferation, differentiation and reproduction. ncRNAs also serve key roles in cancer development. Numerous studies have been carried out on ncRNAs, and associated publications have shown that ncRNAs are closely associated with the physiological and pathological mechanisms of CCA. The findings of these studies can provide new insights into the diagnosis, treatment and prognosis of CCA. The present review summarizes the pathophysiological mechanisms of different types of ncRNAs, including miRNAs, circRNAs and lncRNAs in CCA, and their applications in the diagnosis and treatment of CCA.
\end{abstract}

\section{Contents}

1. Introduction

2. miRNA

3. Circular RNA

4. LncRNA

5. Contribution of next-generation sequencing (NGS) to ncRNAs.

6. Conclusions

Correspondence to: Dr Shuai Huang or Dr Yongfu Zhao, Department of Hepatobiliary and Pancreatic Surgery, The First Affiliated Hospital of Zhengzhou University, 78 Zhongyuan East Road, Erqi, Zhengzhou, Henan 476100, P.R. China

E-mail: fcchuangs@zzu.edu.cn

E-mail: yfzhao3698@126.com

${ }^{*}$ Contributed equally

Key words: cholangiocarcinoma, noncoding RNAs, cancer, tumourigenesis, metastasis, mechanism, future therapeutics

\section{Introduction}

Cholangiocarcinoma (CCA) is a malignant tumour originating from biliary epithelial cells. This malignancy can be divided into three subtypes, namely intrahepatic CCA (iCCA), perihilar CCA (pCCA) and distal CCA (dCCA). The latter two subtypes have been classified as extrahepatic CCA (eCCA) in the past, but are now considered to be different entities according to the biological characteristics of the tumour; they also have different treatments. Of the three subtypes of CCA, pCCA is the most common subtype (1). Surgery is the preferred treatment for CCA, but only $\sim 35 \%$ of patients can undergo surgical removal early in the disease to achieve treatment. For patients with advanced or unresectable CCA, the effectiveness of the existing comprehensive chemotherapeutic regimens is limited: The current standard nursing chemotherapeutic regimen (gemcitabine and cisplatin) has a median overall survival (OS) of $<1$ year. Mesenchymal hyperplasia and genetic heterogeneity are important factors leading to CCA resistance. The extensive tumour microenvironment sends strong survival signals for the tumour, which may limit the efficacy of tumour chemotherapy (2). Therefore, further studies of the potential biomarkers of CCA for early diagnosis, comprehensive treatment and prognosis are required.

According to the central principle in the field of biology, genetic information is transcribed from DNA to RNA and then translated from RNA to protein, and RNA only serves as a carrier in the transmission of genetic information. With the rapid development of life science research, researchers have gradually realised that the complex biological characteristics of higher organisms do not depend on the number of genes but rather on the regulation of gene expression. Noncoding RNA (ncRNAs) are a type of RNAs that do not code proteins and are produced by genomic transcription. There are 20,000-25,000 coding genes in the human genome, 40-90\% of which are regulated by microRNAs (miRNAs) (3). According to nucleotide length, ncRNAs can be divided into three categories: i) Short ncRNAs, which are ncRNAs $<50 \mathrm{nt}$ in length, mainly including miRNAs, small interfering RNAs (siRNAs) and RNAs that interact with Piwi protein; ii) medium ncRNAs, which are ncRNAs 50-200 nt in length, which mainly include ribosomal RNAs, transfer RNAs, small nuclear RNAs and small nucleolar RNAs; and iii) long ncRNAs (lncRNAs), which are ncRNAs of $>200 \mathrm{nt}(4,5)$. Numerous studies $(2,3,5)$ have confirmed that ncRNAs are not junk genes as originally 
thought but are molecules with multiple functions in gene expression regulation that serve important roles in whole cell systems. The discovery of the regulatory functions of ncRNAs has refined our knowledge of heredity. Studies have shown that ncRNAs play an important role in maintaining the normal function of cells, as well as in the occurrence and development of diseases, and thus have potential applications as disease biomarkers.

Due to the rapid development of molecular biology, especially gene sequencing technology, the mechanism of action of ncRNAs in CCA has been gradually revealed, and research on the application of ncRNAs in CCA has substantially expanded. For example, the expression of lncRNA ECIC1 was shown to be significantly increased in CCA tissues (6), and silencing of the lncRNA H19 gene effectively inhibited the proliferation of CCA cells and promoted apoptosis (7). The present review partially summarises and describes the physiological and pathological changes of ncRNAs and their clinical applications in the diagnosis and treatment of CCA.

\section{2. miRNA}

miRNAs are RNA molecules with a length of 22 nucleotides that are involved in transcriptional gene regulation and are widely present in eukaryotes (8). In 1993, Lee et al (8) discovered the first miRNA, lin-4, in Caenorhabditis elegans (nematodes). In 2000, Bushati and Cohen (9) found another miRNA, let-7, thus initiating the study of miRNAs.

miRNAs are usually transcribed by RNA polymerase II, which carries out the primary transcription of primary (pri)-miRNAs (5'-cap structure and 3'-polyA tail). Several transcription factors involved in miRNA transcription can bind to the miRNA gene upstream of specific sites to influence miRNA expression. Then, pri-miRNAs undergo two cleavage steps to generate mature miRNAs. Animal pri-miRNA cleavage first occurs in the nucleus. The RNase III nuclease Drosha and DGCR8, a cofactor, generate precursors of $\sim 70$ nucleotides with an incomplete matching stem structure, called pre-miRNAs. Pre-miRNAs are transported from the nucleus to the cytoplasm via Ran-GTP-dependent exportin-5-mediated transfer, and these molecules undergo a second cleavage in the cytoplasm via the RNase III nuclease Dicer and its cofactor TRBP; then, PACT cleaves the segments of double-stranded RNA into 22 nucleotides that form the mature miRNA and its complementary sequence as dimers $(10,11)$. There are two modes of interaction between miRNAs and target mRNAs. When the two are completely complementary, miRNAs act in a manner similar to RNA interference, that is, they pair and bind with fully complementary homologous mRNAs, leading to the degradation of the target mRNAs. However, when the miRNA and target mRNA are not completely complementary, the miRNA binds to the 3' UTR of target mRNA to suppress post-transcriptional translation. Since numerous miRNAs and target gene mRNAs are not completely complementary, the main mode of action is post-transcriptional translational repression (12). In addition, current research has focused on epigenetic changes in miRNA expression and miRNA expression via methylation and histone modification, both of which are markers of epigenetic gene regulation (13). For example, in CCA cells, miR-370 is a tumour-suppressor gene that inhibits the oncogenic protein kinase 8 (MAP3K8) (14). In addition, the overexpression of interleukin (IL)-6 in CCA reduces the expression of miR-370 through DNA hypermethylation, while restoring the expression of MAP3K8, promoting the growth of tumour cells and the progression of CCA (14). Another study showed that the expression of immunoglobulin-dimethylformamide via miR-370 reflected the hypermethylation-mediated regulation induced by IL-6 in human CCA (15).

miRNAs and CCA. The expression profiles of miRNAs in tumour cells and normal tissue cells are notably different, and most miRNA genes are located at key genetic loci associated with tumour formation. The occurrence of miRNA genes at a high frequency in these regions is closely associated with tumour genomic variation (16). These findings suggest that miRNAs may play an important role in tumour formation. However, studies have found that CCA, a tumour with poor prognosis, is closely associated with various miRNAs. Different miRNAs and their various mechanistic targets in CCA are presented in Table I.

Oncogenic miRNAs. miRNAs can be up- or downregulated in tumours, either of which may serve a crucial role in different tumours. Overexpressed miRNAs often affect the occurrence and progression of CCA through different mechanisms.

By comprehensively analysing the miRNA expression levels in 241 iCCA tumour tissues, Plieskatt et al (16) found that eight dysregulated miRNAs were identified in all Ov-induced ICC plasma samples and not in control plasma, and seven displaying opposite expression changes in plasma compared with tissue (miR-1275, miR-193a-5p, miR199b-5p, miR-320a, miR-483-5p, miR-505-3p and miR-874). In addition, abnormal miRNA expression in tumour tissues was inconsistent with that observed in plasma, with 15 highly regulated miRNAs only detected in the tumour tissue samples. Therefore, this expression profile in plasma can be used as a biomarker for the early diagnosis of iCCA. Petrache Voicu et al (17) found that the overexpression of hsa-miR-21 in the CCA cell lines QBC939 and RBE significantly promoted the migration and invasion of the cells. In addition, the overexpression of hsa-miR-21 decreased the expression of E-cadherin and increased the expression of $\mathrm{N}$-cadherin and vimentin. This indicates that hsa-miR-21 can induce the epithelial-mesenchymal transition (EMT) of CCA. Zhu et al (18) found that the expression of the miR-17-92 cluster in CCA cancer cells was higher than that in eepithelial cells of normal bile duct, indicating that it was an oncogenic miRNA.

Further studies have confirmed that the target of miR-17-92 is PTEN, and identified that a new regulatory axis, IL-6/STAT3-miR-17-92 cluster-PTEN, is important in the occurrence and development of CCA. A study found that miR-31 is highly expressed in CCA tissues and the cell line HCCC-9810, and bioinformatics analysis and immunofluorescence experiments identified RASA1 as a potential target of miR-31 (19). Further experiments in that study confirmed that miR-31 promotes the growth of CCA cells and inhibits their apoptosis by inhibiting RASA1 expression. Another study demonstrated that miR-605 inhibits the tumour progression of CCA cell lines by inhibiting the expression of the oncogene PSMD10 (20). Cheng et al (21) extracted RNA from bile 
Table I. Specific expression, target genes and functions of different types of miRNAs in CCA.

A, Upregulated

\begin{tabular}{|c|c|c|c|}
\hline miRNA & Target gene & Function or mechanism & Refs. \\
\hline miR-26a & GSK-3 $\beta$ & $\begin{array}{l}\text { Activates } \beta \text {-catenin and promotes proliferation } \\
\text { and colony formation of CCA cells }\end{array}$ & $(111)$ \\
\hline $\operatorname{miR}-21$ & $\begin{array}{l}\text { RECK, PDCD4, PTEN, } \\
\text { TIMP3, 15-PGDH }\end{array}$ & $\begin{array}{l}\text { Promotes proliferation, migration } \\
\text { and invasion of CCA cells }\end{array}$ & $(41,112,113)$ \\
\hline $\operatorname{miR}-25$ & DR4 & Inhibits apoptosis of CCA cells & (114) \\
\hline $\operatorname{miR}-31$ & RASA1 & $\begin{array}{l}\text { Promotes the proliferation and inhibits } \\
\text { the apoptosis of cancer cells }\end{array}$ & (19) \\
\hline $\operatorname{miR}-221$ & PTEN & Invasion, migration and EMT & $(115)$ \\
\hline miR-141 & CLOCK & Proliferation and physiological rhythm & $(116)$ \\
\hline miR-200b & PI3k, PTEN & Multidrug resistance & (24) \\
\hline $\operatorname{miR}-210$ & Mnt & Proliferation & $(116)$ \\
\hline $\operatorname{miR}-199 a-3 p$ & mTOR & Multidrug resistance & $(117)$ \\
\hline Let-7a & NF2 & Cell survival, mitogenic and multidrug resistance & $(49)$ \\
\hline $\operatorname{miR}-421$ & FXR & Proliferation and migration & $(118)$ \\
\hline
\end{tabular}

B, Downregulated

\begin{tabular}{|c|c|c|c|}
\hline miRNA & Target gene & Function or mechanism & Refs. \\
\hline $\mathrm{miR}-200 \mathrm{~b} / 200 \mathrm{c}$ & ROCK2, SUZI2 & $\begin{array}{l}\text { Inhibits the migration and invasion of } \\
\text { CCA cells and inhibits cell carcinogenicity }\end{array}$ & $(35)$ \\
\hline miR-101 & VEGF, COX-2 & Inhibits angiogenesis and growth of CCA & $(37)$ \\
\hline miR-494 & CDK6 & Blocks the growth of CCA cells & $(119)$ \\
\hline $\operatorname{miR}-376 c$ & GRB2 & Attenuates epidermal growth factor-dependent cell migration & $(34)$ \\
\hline miR-204 & Slug & $\begin{array}{l}\text { Inhibits epithelial-mesenchymal transition and the migration } \\
\text { and invasion of CCA cells }\end{array}$ & $(38)$ \\
\hline miR-205 & MMP-2 & Multidrug resistance & $(120)$ \\
\hline $\operatorname{miR}-34 a$ & Per1, Smad4 & Proliferation, invasion, migration and the cell cycle & $(121,122)$ \\
\hline $\operatorname{miR}-320$ & $\mathrm{Mcl}-1 / \mathrm{Bcl}-2$ & Apoptosis & $(25)$ \\
\hline miR-370 & MAP3K8 & Proliferation & $(29,127)$ \\
\hline $\begin{array}{l}\text { Let-7a/miR-99a/ } \\
\text { miR-125b }\end{array}$ & IL-6, IL-6R, IGF1R & Invasion and migration & (48) \\
\hline $\operatorname{miR}-410$ & XIAP & Proliferation & $(123)$ \\
\hline miR-148a, miR-152 & DNMT-1 & Proliferation & (124) \\
\hline miR-373 & MBD2 & Proliferation & $(125)$ \\
\hline $\operatorname{miR}-29 b$ & Mcl-1 & proliferation and clone formation & $(27)$ \\
\hline $\operatorname{miR}-214$ & TWIST & Invasion and migration & $(30)$ \\
\hline
\end{tabular}

miRNA, microRNA; CCA, cholangiocarcinoma.

to detect the expression levels of miRNAs, and found that miR-106a expression in patients with CCA was significantly higher than that in patients with gallstones, and the diagnostic sensitivity and specificity were 83.3 and $88 \%$, respectively. In addition, researchers studied the characteristics of secretory vesicles extracted from bile, including their size, number and distribution in the biliary tract, to establish a diagnostic profile of bile molecules and miRNAs in CCA with potential clinical value (22). Using the TCGA database, Canu et al (23) found that miR-204 was essential in the pathogenesis of CCA, and on this basis, they verified this miRNA in CCA cell lines; furthermore, 25 patients with eCCA had a higher miR-221 level than the average level of 32 controls. The researchers also found that miR-221/ $\beta$-catenin formed a positive feedback loop and that PTEN was enhanced, leading to EMT maintenance. These results confirmed that miR-221 overexpression promoted cell migration and invasion (23).

A study found that miR-141 is highly expressed in CCA cells, and target genes of miR-141 include the CLOCK gene (24). This gene not only regulates circadian rhythm but 
also acts as a tumour suppressor gene to inhibit cell division and promote cell apoptosis. Thus, inhibition of miR-141 can increase CLOCK protein expression in CCA cells, inhibiting the tumour suppressor function of the CLOCK protein and promoting the development of tumours. Chen et al (25) found that miR-106a was elevated 110-fold in CCA tissues compared with normal liver tissues, suggesting that it is also a specific oncogene in CCA. miR-106a has also been found to be overexpressed in gastric, colorectal, colorectal and pancreatic cancer tissues, but downregulated in glioma in which it was shown to have an anticancer role $(21,25)$. However, high tissue levels of miR-106a have been reported to be associated with glioma invasion through the targeting of metalloproteinase-2, 3 and 4 (26).

Tumour suppressor miRNAs. In contrast to the genes that are highly expressed in CCA, some miRNAs exhibit low expression in CCA, and the roles of miRNAs in CCA involve different targets and mechanisms. Okamoto et al (27) confirmed that the overexpression of miR-29b significantly inhibited the proliferation and colony formation of CCA cells through MTT and colony formation assays. Furthermore, flow cytometric analysis showed that the overexpression of miR-29b significantly induced apoptosis and blocked the cell cycle in the $\mathrm{S}$ phase, suggesting that miR-29b is a tumour suppressor miRNA in CCA. Another miRNA, miR-373 has been found to target and negatively regulate MBD2, which is an important modifier of genes silenced by methylation, and affects the expression of the downstream oncosuppressor gene RASSFlA (28). CCA cancer cells transfected with miR-373 precursors exhibited inhibited growth with downregulated MBD2 and increased expression of RASSFlA, indicating that miR-373 can act as a tumour suppressor gene in CCA and exert a corresponding inhibitory effect on tumour development (28).

The expression of miR-370 in CCA specimens and CCA cell lines has been shown to be downregulated to varying degrees (29). The target gene of miR-370 is the oncogene MAP3K8, which is negatively regulated by miR-370. IL-6 regulates miR-370; when IL-6 is overexpressed, miR-370 is downregulated, and the expression of its target gene MAP3K8 is increased, thus promoting the proliferation of biliary cancer cells in vitro and the growth of allogeneic tumours in mice. Increased expression of miR-370 inhibited the proliferation of CCA cells. Ngankeu et al (30) found that the antiapoptotic gene McL-1 was targeted by miR-29b, and detected McL in various tumours. Abnormal overexpression of McL-1 was also shown to be associated with tumour prognosis and recurrence (30). In CCA, the overexpression of McL-1 led to tumour cell resistance to tumour necrosis factor-related apoptosis-inducing ligand (TRAIL)-mediated apoptosis, while reduced expression of this gene increased the sensitivity of cells to apoptotic mechanisms (30). Although the expression of miR-29b is downregulated in CCA cells, increased expression of miR-29b was able to reduce the level of the target gene McL-1, thus indicating its anticancer role (30).

It has been reported that Hedgehog signalling, Toll-like receptor and c-Myc can downregulate the expression of miR-29b, and these three genes allow CCA cells to escape TRAIL-mediated apoptosis (31). Kwon et al (32) identified miR-34a as an important tumour suppressor in human CCA and disclosed a novel epigenetic regulatory mechanism in which miR-34a inhibits CCA growth by targeting the Notch pathway. This finding also suggests that restoration of endogenous miR-34a expression by targeting the epigenetic machinery, such as the enhancer of zeste homolog 2 (EZH2) inhibitor, or delivery of an exogenous miR-34a mimic may represent novel therapeutic strategies for the treatment of human CCA. Using quantitative PCR (qPCR), Li et al (33) found that the expression of miR-214 in metastatic CCA tissues was significantly lower than that in non-metastatic CCA tissues. When miR-214 was downregulated in CCA cells, the transcription level of the mesenchymal-epithelial transition (MET) regulatory gene TWIST increased, resulting in decreased E-cadherin expression in epithelial cells. The researchers concluded that miR-214 regulated the invasion and metastasis of cells by controlling the transcription of the target gene TWIST.

Iwaki et al (34) found that another miRNA, miR-376c, was also associated with the metastasis of CCA; miR-376c was expressed at low levels in the CCA cell line HuCCT1, which accelerated the epidermal growth factor-dependent tumour metastatic process by acting on growth factor-binding receptor 2. In addition, epigenetic analysis confirmed that the low level of miR-376c in CCA cell lines was associated with hypermethylation of the $\mathrm{CpG}$ island upstream of the gene (34). Another study reported the low expression of the miR-200 family, including miR-200a, miR-200b, miR-200c and miR-429, in CCA and verified that $\mathrm{miR}-200 \mathrm{~b} / \mathrm{c}$ could inhibit the invasion and metastasis of CCA cells by directly inhibiting the expression of rho-kinase 2 (35). In addition miR-200b/c was shown to inhibit the formation of tumours, via the target SUZ12 (35). miR-144 has also been shown to be significantly downregulated in CCA, inhibiting not only the growth of tumour cells but also the invasion and metastasis of CCA cells by acting on platelet-activating factor acetylhydrolase isoenzyme $1 \mathrm{~b}$ (36). In another study, Zhang et al (37) found that miR-101 exhibited low expression in $43.5 \%$ of CCA tissue specimens and in three CCA cell lines compared with noncancerous controls. Further analysis of its biological function demonstrated that miR-101 inhibits tumour angiogenesis in CCA cell lines by acting on vascular endothelial growth factor to inhibit the growth of CCA (37). The miR-29 and miR-320 expression levels in CCA cells or tissues are suppressed, and the Bcl-2 antiapoptotic genes in the Mcl-1 family are associated with miR-29 and target genes of miR-320 (25,38), Mcl-1 plays an important role in resistance to CCA cell apoptosis (39), and the increased expression of miR-320 and miR-29 in CCA cells reduces the expression of Mcl-1, leading to decreased cell resistance. The expression of miR-204 has been shown to be low in CCA tissue $(25,38)$. Furthermore, miR-204 is able to inhibit the expression of Bcl-2, thus increasing the drug resistance of cells (38).

$m i R-21$. Numerous studies have shown that miR-21, a miRNA upregulated in CCA, is overexpressed in numerous types of malignant tumours, such as nasopharyngeal, oesophageal squamous cell, gastric, liver, pancreatic, colorectal, lung, breast and ovarian cancer, and acts as an oncogene. This miRNA is associated with poor prognosis of malignant tumours (40). Researchers have reported that the overexpression of miR-21 promoted the proliferation, migration and metastasis of cancer 


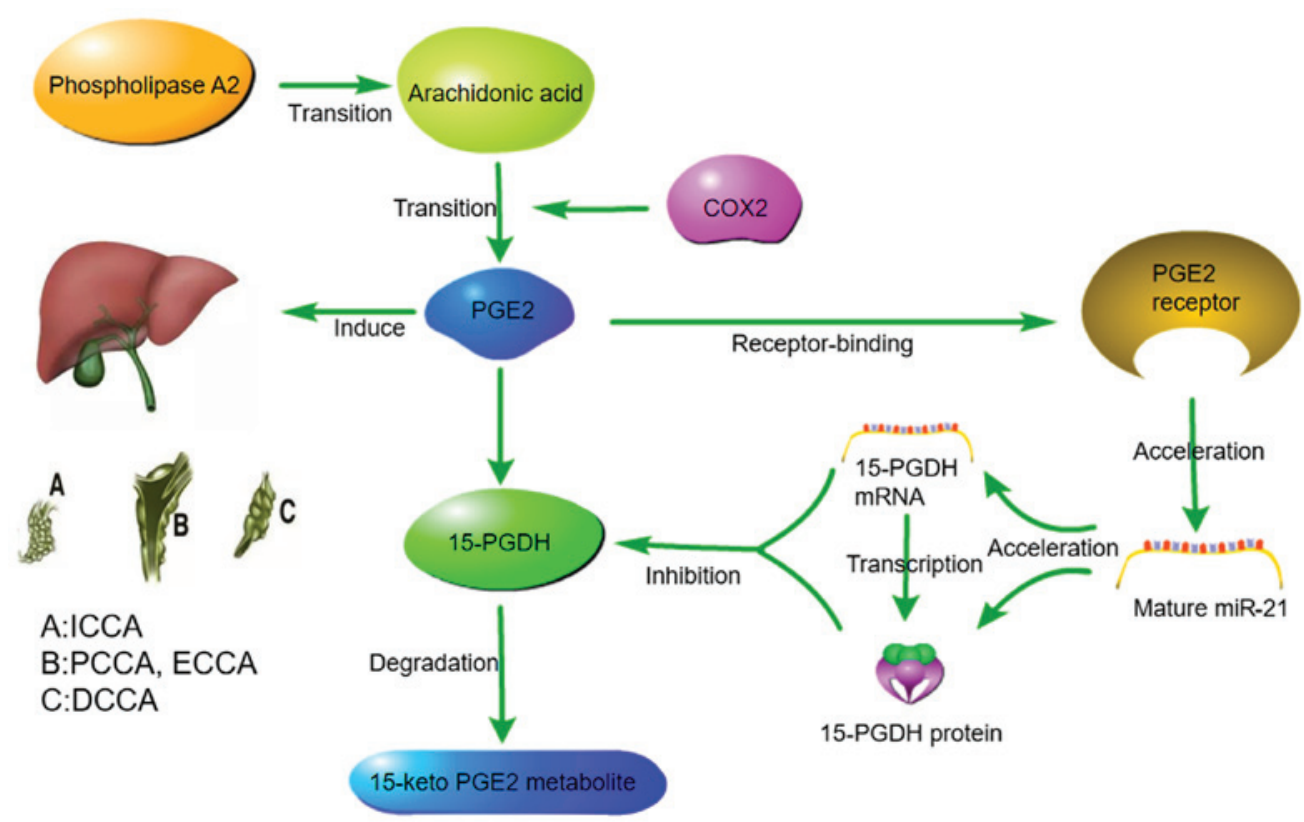

Figure 1. Mechanism of the feed-forward carcinogenesis of miR-21 and PGE2 in cholangiocarcinoma. COX2, cyclooxygenase 2; PGE2, prostaglandin E2; PGDH, hydroxyprostaglandin dehydrogenase; ICCA, intrahepatic cholangiocarcinoma; PCCA, perihilar cholangiocarcinoma; ECCA, extrahepatic cholangiocarcinoma; DCCA, distal cholangiocarcinoma; miR/miRNA, microRNA.

cells, while its downregulation had the opposite effect (40). In addition, miR-21 may be involved in the phenotypic characteristics of cancer cells, including cell proliferation, apoptosis and the cell cycle, and may play a crucial role in the expression of gene products $(40,41)$. Selaru et al (41) found that miR-21 was significantly overexpressed in CCA tissues compared with normal tissues, and revealed that the knockdown of miR-21 can reduce the metastatic potential of CCA cells by regulating PDCD4 and tissue inhibitor of metalloproteinases 3 (TIMP3). TIMP3 plays a crucial role in the invasion and metastasis of cancer (42). In addition, Ars2 protein is essential for the development of miRNAs (42). Ars2 and miR-21 have been identified to be overexpressed in CCAs, with the knockdown of Ars2 resulting in downregulation of miR-21 expression and inhibiting tumour formation, while the overexpression of Ars2 did not increase miR-21 expression or promote tumour formation (43). Furthermore, the overexpression of miR-21 can promote the invasion and metastasis of the RBE CCA cell line, while inhibition of miR-21 has the opposite effect (44). miR-21 affects the invasion and metastasis of CCA cells through the tumour suppressor gene PTEN. The high expression of miR-21 in CCA has been shown to inhibit the expression of tumour suppressor genes such as PDCD4 and TIMP3, as well as the expression of PTEN, and influences the invasion and metastasis of RBE cells by inducing EMT (41).

A study revealed that increased prostaglandin E2 (PGE2) signalling pathway activation in CCA enhanced the expression of miR-21. Sequence alignment analysis identified the binding site of miR-21 in the 3' UTR of 15-hydroxyprostaglandin dehydrogenase (PGDH), and the overexpression of miR-21 reduced the mRNA and protein levels of 15-PGDH. miR-21 targets 15-PGDHand leads to blocked PGE2 degradation. The accumulation of PGE2 further increased the expression of miR-21. These signals cascade to form a feed-forward loop that drives the development of CCA and tumour progression (41), as illustrated in Fig. 1.

Let-7. Members of the let-7 family are highly conserved in sequence and function from $C$. elegans to humans, and are critical regulators of embryonic development, stem cell maintenance, differentiation, glucose metabolism and the development of pathological processes, including tumourigenesis (45). Analysis using TargetScan Human 7.0 and the published literature have shown that EZH2 is a direct target of let-7c in cancer cells (46). Xie et al (47) revealed the complex role of microporous let-7c in human CCA; overexpression of let-7c inhibited invasion in vitro but increased distant metastasis in vivo. In addition, let-7c inhibited the tumourigenic capacity of CCA cells, including spheroid formation and tumour initiation; similar results were obtained by regulation the expression of EZH2 and dvl3. These results provide strong experimental evidence for the involvement of let-7c in the distant metastasis of CCA, suggesting that miRNAs are novel biomarkers that can be used to identify patients with metastatic disease (47). A genome-wide screen identified that family members of the let-7c/miR-99a/miR-125b cluster are similarly downregulated in CCA and target the IL-6/STAT3 pathway (49). Their overexpression decreased STAT3 activation and inhibited the malignant transformation of CCA cells in vitro and their tumourigenicity in vivo. These results indicate the potential of the let-7c/miR-99a/miR-125b cluster as a molecular target for CCA therapy (48). Furthermore, treatment of the cells with let-7c/miR-99a/miR-125b, resulted in prolonged inhibition of STAT3 phosphorylation (48), which may counteract many of the biological effects of the STAT3-mediated tumourigenic pathway (49). Therefore, the endogenous miRNA targeting STAT3 may provide a natural and safe treatment option, and these findings suggest a strategy for the development of a miRNA-based therapy using the IL-6/STAT3 CCA 


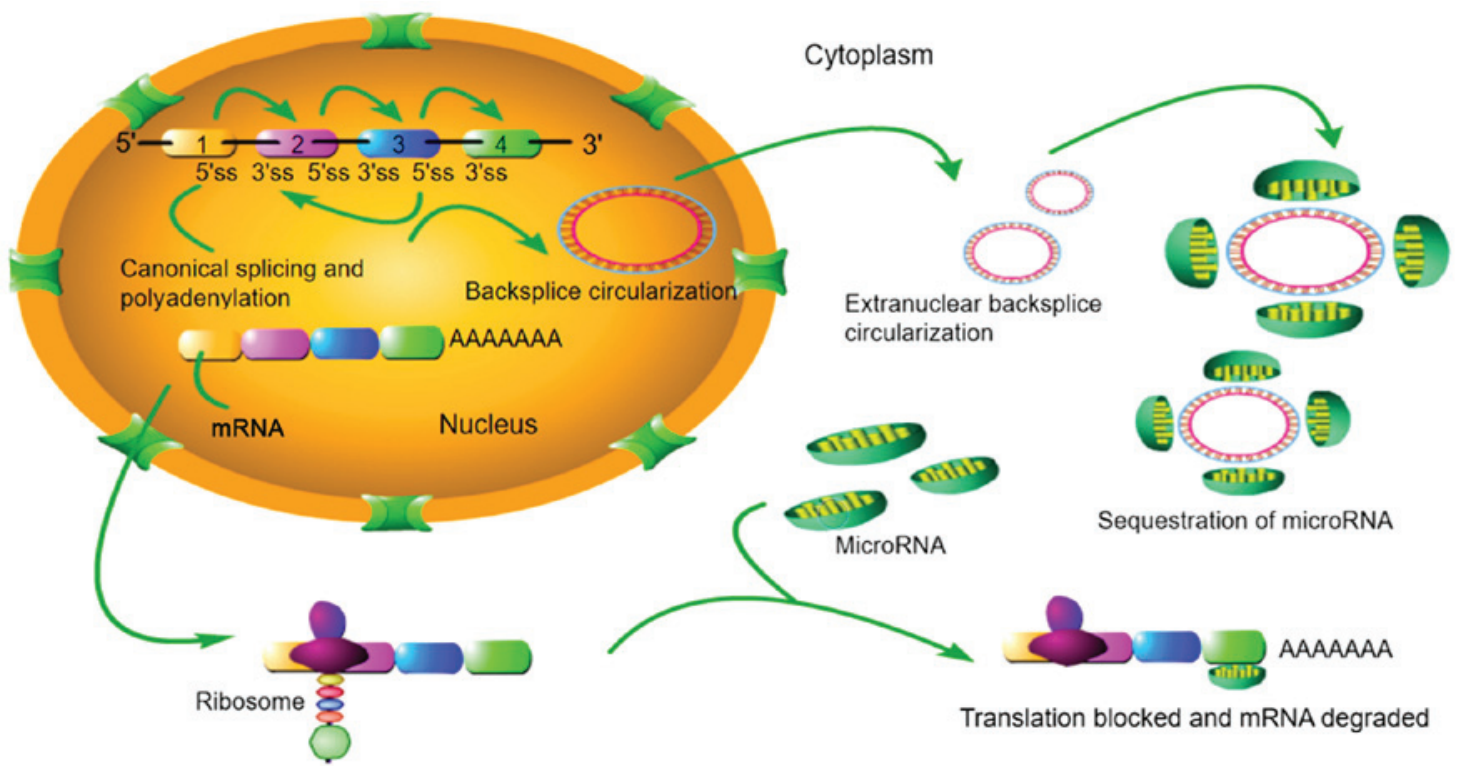

Figure 2. Interactions among circular RNAs, microRNAs and mRNAs.

pathway (48). Meng et al (49) found that let-7 expression was upregulated in CCA cells overexpressing IL-6. Another study (47) indicated that neurofibromatosis 2 is a target gene of let-7a, and since NF-2 is a negative regulator of STAT3, let-7a could increase STAT3 pathway activity by downregulating NF-2 expression, thus enhancing the drug resistance of CCA cells with overexpression of IL-6. Therefore, Let-7 may have a dual mechanism of action, with different regulatory effects on CCA in different states.

miR-200 family. The miR-200 family includes five members: miR-200a, miR-200b, miR-200c, miR-141 and miR-429. A study confirmed that the miR-200 family can increase the expression of E-cadherin by inhibiting the expression of zinc finger e-box-binding homeobox (ZEB)1 and ZEB2, thus promoting EMT (50). Another study has shown that the miR-200 family and the low expression of E-cadherin in a highly metastatic breast cancer cell line (4TO7) promote cell metastasis and invasion (51). Furthermore, miR-141 and miR-200b from the miR-200 family have been found to be expressed at high levels in CCA cells (24). A target of miR-141, CLOCK, plays an important role in regulating the physiological rhythm of the body and also acts as a tumour suppressor gene to inhibit cell division and promote apoptosis (24). Therefore, miR-141 may promote the proliferation of CCA cells by inhibiting the expression of CLOCK. The target gene of miR-200b is PTPN12, and PTPN12 can inhibit the Ras pathway by dephosphorylation of c-Abl and Src to achieve tumour suppression. Therefore, the inhibition of miR-200b expression is likely to lead to a reduction in the drug resistance of CCA cells (24).

\section{Circular RNA}

Circular RNAs (circRNAs) are a class of ncRNA molecules without a 5'-terminal cap and 3'-terminal poly(A) tail, which form a covalently bonded ring structure and are widely present in eukaryotic cells (52). CircRNAs are structurally stable, highly abundant, and expressed in a tissue-specific manner. By binding to miRNAs and other molecules, circRNAs regulate gene expression at the transcriptional and post-transcriptional levels, thereby affecting various cell processes (53).

CircRNAs are relatively stable in animal cells and regulate the expression of target genes through various pathways. circRNAs have covalent cyclic structures without 5'-3' polarity or poly(A) tail. The circular structure includes multiple miRNA-binding sites named miRNA response elements, via which circRNAs can act as sponges and thereby serve as candidate RNA binding proteins to regulate mRNA expression; circRNAs can bind directly to targeted miRNAs to regulate mRNA expression (53), as illustrated in Fig. 2. Therefore, by interacting with miRNAs, circRNAs play an important role in the regulation of tumour progression and various tumour signalling pathways $(52,54)$.

Xiong et al (55) reported that circRNA ZNF609 upregulated FOXP4 expression and regulated the progression of renal cancer cells through sponging miR-138-5p. A study by $\mathrm{Xu}$ et al (56) revealed that the expression of circ_0005230 was increased in breast cancer, and could act as a competing endogenous RNA (ceRNA) to increase the expression of CBX8 through sponging miR-618. However, in another study by Xu et al (57), miR-618 was almost unaffected by circ_0005230 in two selected CCA cell lines, suggesting that circ_0005230 may have a tissue-specific mechanism. Of all the predicted miRNAs in that study, only miR-1238 and miR-1299 were negatively correlated with the circ_0005230 levels. Little research has been conducted on the role of miR-1238 in cancer progression. A report by Shi et al (58) identified miR-1238 as a tumour suppressor in the development and progression of cancer. The researchers found that miR-1238 partially inhibited the growth of non-small cell lung cancer cells by inhibiting LHX2. Xu et al (57) confirmed that miR-1238 was a tumour-suppressive miRNA in CCA, and rescue experiments showed that the carcinogenic effect of circ_0005230 was partly due to its inhibition of miR-1238 and miR-1299. Prior to this, the circRNA Cdrlas was reported to be increased in 
Table II. Functions and targets of some typical lncRNAs.

\begin{tabular}{|c|c|c|c|}
\hline LncRNA & Target & Function & Ref. \\
\hline H19 & IL-6 & $\begin{array}{l}\text { Key inflammatory factor IL- } 6 \text { is activated to regulate the migration } \\
\text { and invasion of cancer cells }\end{array}$ & $(69)$ \\
\hline HULC & CXCR4 & $\begin{array}{l}\text { Activation of the chemokine receptor } \mathrm{CXCR} 4 \text { regulates the migration } \\
\text { and invasion of cancer cells }\end{array}$ & $(69)$ \\
\hline TUG1 & Sirt3 & TUG1/miR-145/Sirt3/GDH network & $(126)$ \\
\hline CCAT1 & EMT & Leads to EMT activation of ICC cells & $(70)$ \\
\hline NEAT1 & BAP1, EZH2, cadherin & Invasion and migration & $(73)$ \\
\hline MALAT1 & CXCR4 & $\begin{array}{l}\text { Growth, migration and invasion of CCA cells are regulated } \\
\text { by miR-204-dependent CXCR4 }\end{array}$ & $(77)$ \\
\hline PVT1 & EZH2, ANGPTL4 & Proliferation, invasion and migration & $(71)$ \\
\hline PCAT1 & miR-122, Wnt, $\beta$-catenin & Promotion of the $\mathrm{Wnt} / \beta$-catenin pathway & $(127)$ \\
\hline UCA1 & AKT, GSK-3 $\beta$, CCND1 & Proliferation, invasion and migration & $(128)$ \\
\hline SPRY4-IT1 & $\mathrm{EZH} 2$ & Strengthens EZH2 expression & $(129)$ \\
\hline T-UCRs & $\beta$-catenin & $\begin{array}{l}\text { Wnt } / \beta \text {-catenin pathway downstream mediators } \\
\text { and the development of specific cancers }\end{array}$ & $(130)$ \\
\hline LINC01296 & MYCN & LINC01296/miR-5095/MYCN network & $(131)$ \\
\hline
\end{tabular}

lncRNA, long non-coding RNA.

CCA (59); however, whether miR-1299 is sponged by Cdrlas in CCA remains unknown. In addition, how miR-1238 and miR-1299 inhibit the progression of CCA cells and the downstream targets of these miRNAs remain unclear.

In the study by Jiang et al (59), Cdrlas expression in tumour tissues was found to be higher than that in adjacent normal tissues. In addition, the overexpression of Cdrlas exhibited a close association with advanced TNM stage, lymph node infiltration and postoperative recurrence. The OS of patients with CCA and high Cdrlas expression was poorer than that of patients with CCA and low Cdrlas expression, which further suggests that Cdrlas may serve as a potential biomarker of malignancy to predict aggressive tumour progression and poor prognosis in patients with CCA. Xu et al (60) verified that circ-0001649 downregulation promoted the migration, proliferation and invasion of CCA cells. In a study by Wang et al (61), circ-0000284 was shown to regulate LY6E expression as a ceRNA by sponging miR-637, and was suggested to be important in the pathogenesis of CCA. Furthermore, the study suggested that exosome-transmitted circ-0000284 may stimulate the malignant behaviours of surrounding normal cells via the enhancement of migration and proliferation and inhibition of apoptosis of these cells.

CircRNAs are a new topic of interest in RNA research, along with miRNA and lncRNAs. Certain circRNAs have been found to play important regulatory roles in the tumour process, but their roles in the progression and metastasis of iCCA have not been fully defined, and further studies are required.

At present, high-throughput sequencing technology has been used to identify key circRNAs from iCCAs with high and low metastatic potential, and the let-7/STAT3 signalling pathway has been used as the entry point to study the mechanism of key circRNA-key signalling pathway-target gene-cell metastasis phenotypes. CircRNAs are expected to be markers for the early diagnosis of iCCA, and research on the pathogenesis and metastasis of circRNAs in iCCA is ongoing.

\section{LncRNA}

LncRNAs are a subgroup of ncRNAs $>200$ nucleotides in length. LncRNAs are mainly formed by RNA polymerase II transcription and are widely distributed in the nucleus and cytoplasm. Similar to mRNAs, IncRNAs have a 5'-cap structure and a 3 '-end nucleotide polymer tail structure that allows gene splicing but lack a complete reading frame, and thus, the lncRNA itself does not encode a functional protein. Following numerous in-depth analyses, lncRNAs have been found to regulate gene expression mainly at the following three levels: i) Transcriptional level; a lncRNA binds to the adjacent gene promoter region to form a stable RNA-DNA three-strand structure, thereby inhibiting the binding of transcription factors and the gene expression of related proteins (62). ii) Epigenetic modification level; lncRNA inhibits gene translocation, (the rearrangement of chromosomes caused by segmental transfer between non-homologous chromosomes, where genes are transferred from one chromosome to another) by affecting the chromatin domain methylation, acetylation and ubiquitin-like status (62). iii) Post-transcriptional level; lncRNA and target mRNA bind to each other to form RNA double-stranded bodies, covering up key elements of the mRNA; affecting the processing, cleavage, transport, translation and degradation of mRNA precursors; and regulating the post-transcriptional gene expression (62). LncRNAs can be categorised as sense, antisense, intronic, intergenic and bidirectional (63). Moreover, lncRNAs can sponge miRNAs, resulting in post-transcriptional alteration of their target proteins. 


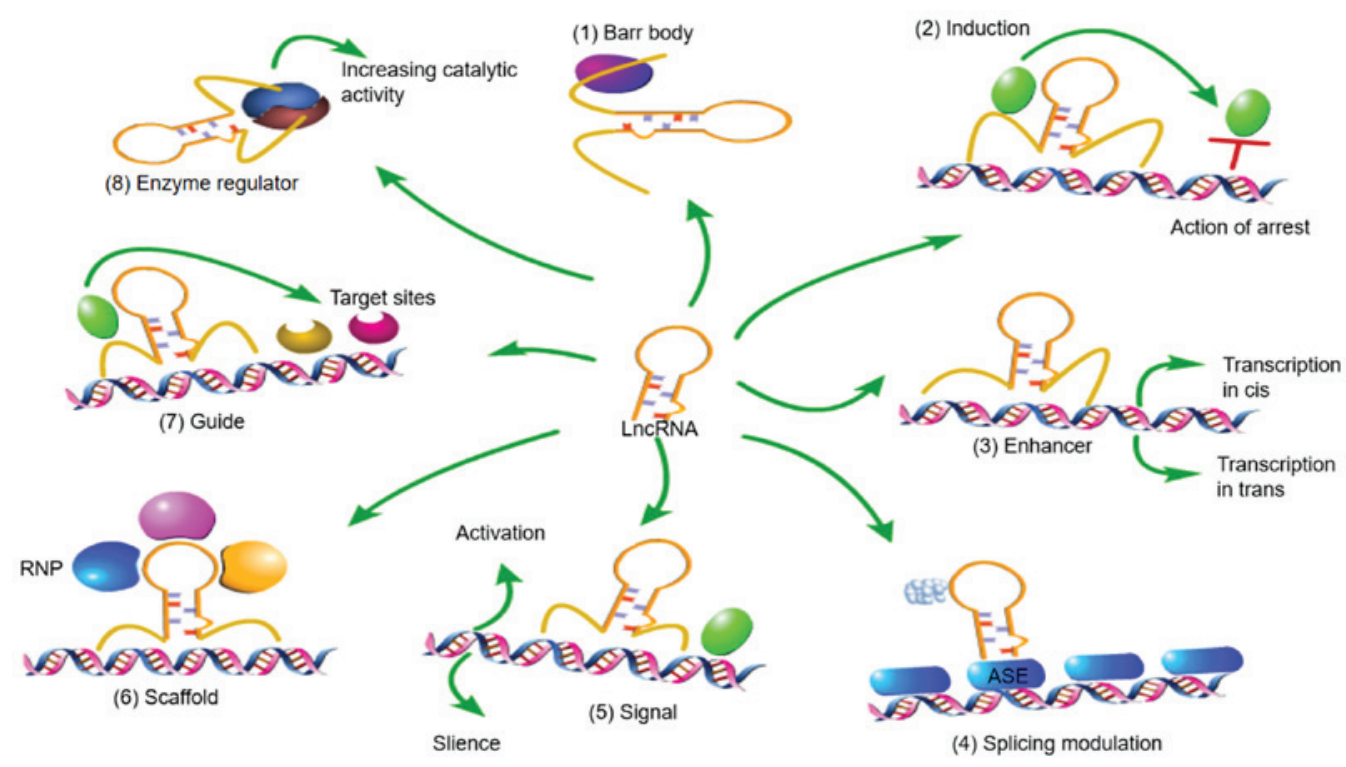

Figure 3: Regulatory mechanism of lncRNA in the nucleus. lncRNA, long noncoding RNA; RNP, ribonucleoprotein; ASE, alternatively spliced exon.

Various lncRNAs have been shown to have abnormal expression or functions in gastric cancer, liver cancer, lung cancer, CCA, laryngeal cancer, colorectal cancer and other malignant tumours, and the expression levels vary in different tumours (44). In 2016, Wang et al (64) examined the IncRNA profile of 77 iCCA tissues, and microarray analysis indicated that 2,773 $\operatorname{lncRNAs}$ were upregulated in iCCA tissues, while 2,392 lncRNAs were downregulated.

LncRNAs and CCA. Studies have shown that the occurrence and development of CCA is closely associated with the abnormal expression and function of lncRNAs, and the expression of lncRNAs in tumour tissues of CCA is very different from that in normal tissues. Hao et al (65) found through high-throughput sequencing that $230 \mathrm{lncRNAs}$ were differentially expressed in iCCA tumour tissues compared with adjacent normal tissues; 97 were upregulated and 133 were downregulated. Some of the abnormally expressed lncRNAs were identified to be involved in the proliferation, apoptosis, EMT, invasion, metastasis, drug resistance and other biological processes of tumour cells (65). Different lncRNAs and their various mechanistic targets in CCA are presented in Table II.

The regulatory mechanisms of IncRNAs in the nucleus include the following $(44,65)$ : i) lncRNA Xist is a component of the female Barr body; ii) lncRNAs can inhibit regulatory proteins, such as transcription factors and chromatin modification factors, to prevent them from binding to DNA; iii) lncRNAs can act as enhancers, inducing cis-trans transcription; iv) lncRNAs regulate the selective splicing of primary transcripts; v) lncRNAs act as a molecular signal to activate or silence gene expression through regulatory signal transduction pathways; vi) lncRNAs act as scaffolds by binding with different proteins to form ribonucleoprotein complexes, which also affect gene expression; vii) lncRNAs guide proteins, generally chromatin modifiers, to specific target sites; and viii) lncRNAs interact with enzymes, such as kinases, to regulate or enhance their catalytic activity and alter their signal transduction pathways (Fig. 3).
Oncogenic lncRNAs. Yao et al (66) detected overexpression of the IncRNA TP73-AS1 in the tumour tissues and adjacent normal tissues of 75 patients with CCA through reverse transcription (RT)-qPCR, and found that the degree of upregulation of this gene was closely associated with tumour size and TNM stage. Silencing TP73-AS1 inhibited the proliferation of CCA cells, activated caspase- 3 and caspase- 9 , and promoted the apoptosis of tumour cells. Li et al (67) found that lncRNA EPIC1 expression was significantly increased in CCA tissues compared with adjacent normal tissues. EPIC1 knockdown resulted in growth inhibition and the apoptosis of CCA cells, thereby reducing their malignant biological behaviours. Furthermore, an interaction was identified between EPIC1 and myc oncogenes, and the expression of the myc gene was decreased in EPIC1-knockout CCA cells. However, the specific mechanism of myc and ECIC1 in CCA require further study.

$\mathrm{Xu}$ et al (68) found that lncRNA H19 was overexpressed in the tumour tissues of 56 patients with CCA, and the expression level of H19 was closely associated with clinicopathological features. Silencing H19 gene effectively inhibited the proliferation of CCA cells and promoted apoptosis. In another study, lncRNA H19 gene silencing was shown to upregulate E-cadherin, downregulate $\mathrm{N}$-cadherin and vimentin, reverse the EMT process, and weaken the metastasis and infiltration of CCA cells (69). Zhang et al (70) studied the overexpression of the IncRNA CCAT1 in the tumour tissues of 120 patients with primary iCCA and adjacent normal tissues, and found that the highly expressed lncRNA CCAT1 was closely associated with tumour progression. Silencing CCAT1 in iCCA cells decreased the levels of $\mathrm{N}$-cadherin, mucin and vimentin and increased those of E-cadherin, which effectively reversed the EMT process of iCCA. Furthermore, a luciferase reporter gene assay found that IncRNA CCAT1 and the oncosuppressive gene miR-152 bind to each other, inducing iCCA cell metastasis, invasion and EMT (70). EMT is an important process in the tumour microenvironment. Alteration of lncRNAs in tumour tissues can reverse the EMT process, and the progression of CCA can be delayed, suggesting a new strategy for the 
clinical treatment of CCA. Ma et al (71) found that lncRNA AFAP1-AS1 was excessively expressed in the tumour tissues of iCCA in 56 patients who had not received local or systemic treatment. After silencing AFAP1-AS1, biological behaviours such as proliferation, invasion and metastasis of CCA cells were inhibited. This lncRNA mainly inhibited cell invasion and metastasis by reducing the expression of matrix metalloproteinase (MMP)-2 and MMP-9, and decreasing the malignancy and biological behaviour tumour cells. Zhang et al (72) analysed the tumour tissues of 33 patients with CCA and found that the expression of IncRNA NEAT1 was significantly increased in tumour tissues compared with adjacent normal bile duct tissues. Moreover, silencing of NEAT1 resulted in the invasion and metastasis of CCA cells. Further experiments in the study showed that lncRNA NEAT1 recruited the E-cadherin promoter through EZH2, and the downregulation of E-cadherin reduced the adhesion strength of the cells, resulting in increased cell activity.

Parasramka et al (73) reported the relationship between lncRNAs and iCCA, and also noted that CCA cells with low expression of BRCA-1 associated protein-1 (BAP1) were highly sensitive to gemcitabine and cisplatin; they also suggested that lncRNA NEAT1 may be a functional downstream molecule of BAP1. Furthermore, NEAT1 knockout in CCA cell lines resulted in significantly higher gemcitabine cytotoxicity than that of normal CCA cell lines, suggesting that NEAT1 can be used as a sensitive tissue biomarker for iCCA and the early diagnosis of CCA. Ma et al (74) found that the expression of carbamoyl phosphate synthetase 1 (CPS1) and its transcribed lncRNA (CPS1 intron 1; CPS1-IT1) were significantly increased in iCCA tissue compared with normal tissue, Survival curve analysis showed that lncRNA-CPS1 expression in tumour tissues was increased in patients with a poor prognosis, and CPS1 and CPS1-IT1 were closely associated with abnormal liver function and prognosis, suggesting that. CPS1-IT1 may be a potential biomarker of iCCA. LncRNA MALAT1 is upregulated in liver, uterine, lung, breast, prostate, pancreatic and cervical cancer, and other tumours (75). Further studies have confirmed that MALAT1 is also an independent prognostic factor for some cancers (76). In CCA, especially in hilar CCA (hCCA), the expression level of MALAT1 is much higher than that of adjacent tissues (77). In vitro and in vivo, MALAT1 has been shown to have protumourigenic effects on the proliferation, invasion and migration of CCA cells (77). In addition, MALAT1 overexpression is associated with low OS, poor TNM staging, large tumour volume and metastasis in patients with hCCA (77). Therefore, it may be concluded that lncRNA MALAT1 is a promising prognostic tissue biomarker for hCCA.

Tumour suppressor IncRNAs. The results of a study by Qin et al (78) showed that the IncRNA FENDRR had reduced expression in CCA tissues and cells, and was negatively associated with the expression of the apoptosis inhibitory protein survivin. It also suggested that FENDRR may inhibit survivin through histone methyltransferase, thereby inhibiting the proliferation, metastasis and invasion of CCA cells. Another study (79) demonstrated that the lncRNA maternal gene 3 (MEG3) is consistently expressed in normal tissues, while its expression is downregulated or absent in tumour cells, including CCA, hepatocellular carcinoma, nasopharyngeal carcinoma, colon cancer. Xia et al (80) found that the knockdown of MEG3 could activate the Wnt/ $\beta$-catenin pathway, and that downregulated MEG3 expression increased cisplatin resistance in lung adenocarcinoma cells. Another study revealed that MEG3 may act as a tumour suppressor gene in CCA cells to downregulate the expression of ABCG2 and enhance the sensitivity of CCA cells to Adriamycin (81). These findings provide a theoretical and experimental basis for the molecular-targeted therapy of CCA.

Another lncRNA, NEF, has been suggested to be an upstream inhibitor of Runt-related transcription factor 1 (RUNX1) in iCCA cells (82). The regulatory effect of lncRNA NEF on RUNX1 in iCCA may be mediated by disease-related factors, as the expression levels of lncRNA NEF and RUNX1 were found to be positively correlated only in tumour tissues and not in the adjacent healthy tissues of iCCA patients. LncRNA NEF expression was downregulated while RUNX1 expression was upregulated in iCCA, and it was suggested that NEF may be involved in ICCA through interaction with RUNX1. Another study found that the expression of 1ncRNA MIR22HG in CCA tissues and cell lines was significantly decreased (83). In CCA, the overexpression of MIR22HG inhibited cell proliferation, migration and invasion, whereas knockdown of MIR22HG had the opposite effect, negatively regulating the mRNA and protein levels of the $\mathrm{Wnt} / \beta$-catenin signalling pathway components ( $\beta$-catenin, cyclin D1 and c-myc). The effects of MIR22HG overexpression on CCA progression were partially rescued by activating the $\mathrm{Wnt} / \beta$-catenin signalling pathway. More importantly, the expression of MIR22HG was found to be associated with TNM stage in CCA patients and thus has prognostic significance.

H19 and HULC. H19, one of the earliest identified lncRNAs with a long history of research, serves a crucial role in oesophageal cancer, breast cancer, bladder cancer, prostate cancer, CCA and other diseases. This lncRNA is overexpressed in tumour tissues, and the degree of expression is closely associated with clinicopathological features.

Increasing evidence indicates that H19 is involved in tumour proliferation and differentiation together with EMT and MET, suggesting that it plays an important role in the occurrence and development of tumours (75). H19 has an evolutionarily conserved secondary structure, suggesting its structure-dependent functions, which include binding to EZH2 (84), interacting with methyl-CpG-binding domain protein 1 and recruiting this protein to some of its targets that maintain the repressive $\mathrm{H} 3 \mathrm{~K} 9 \mathrm{me} 3$ histone marks in their loci (85). H19 has been shown to interact with and inactivate the $\mathrm{P} 53$ protein, suggesting that $\mathrm{H} 19$ plays a role in tumourigenesis (75). HULC has been reported to promote hCCA proliferation and regulate the cell cycle by downregulating the tumour suppressor gene CDKN2C (p18) and participating in the ATM/ATR, p53 and other signalling pathways (86). One study revealed that the let-7a/let-7b pathway potentially targets H19, which leads to partial inactivation of IL-6 in oxidative stress-mediated CCA inflammation, and found that HULC is targeted by miR-372 and miR-373 during the migration and invasion of CCA cells, further activating the chemokine receptor CXCR4 (69). Furthermore, it found that H19 and 
HULC are stimulated by short- and long-term oxidative stress, and regulate the expression of pivotal genes in the inflammatory process, suggesting that there is a positive feedback loop between inflammation and oxidative stress, and the activation of this feedback loop via lncRNAs might promote tumourigenesis in CCA (69).

Studies have found that the imprinting factor $\mathrm{H} 19$ controls gene regulation networks via a trans effect in most malignant tumours and promotes oncogenes, increasing tumour invasion and metastasis at multiple levels as follows: i) Maintenance of cancer stem cells (CSCs); most well-differentiated tumour cells in tumour tissues spread to the target tissues and organs but cannot form metastatic lesions, and only some have the self-renewal and multidirectional differentiation potential of CSCs, which are required for distant metastasis. Therefore, the maintenance of CSC stem cell characteristics is key to tumour invasion and metastasis $(87,88)$. ii) Control of epithelial-interstitial transition; EMT is closely associated with cell polarity and epithelial cell adhesion. Under the action of various factors, the epithelial and mesenchymal characteristics are lost, as shown by cell polarity changes, loss and reduction of the relationship between surrounding mesenchymal cells and other cells, cell invasion and random migration (89). iii) Regulation of tumour neovascularization; research data have shown that the tumour neovascularization is positively associated with tumour invasion and metastasis because the formation of tumour blood vessels not only provides sufficient nutrients and oxygen for tumour growth but also provides good channels for tumour cell invasion and metastasis (90). Jia et al (90) studied the influence of $\mathrm{H} 19$ on the biological behaviour of glioma and found that knockout of H19 inhibited the invasion of glioma cells and the formation of tubular structures. Subsequent dual-luciferase reporter experiments (90) found that H19 could directly act on and inhibit the expression of miR-29a, which in turn targeted the 3' UTR of the vasohibin 2 (VASH2) gene, inhibited the expression of VASH2, and blocked the formation of tumour blood vessels. Therefore, H19 is believed to promote angiogenesis and invasion and metastasis of glioma cells by reversing the inhibitory effect of miR-29a on VASH2.

NNT-AS1. In several studies (91-93), IncRNA NNT-AS1 was found to be significantly upregulated in CCA, and the high expression of NNT-AS1 was associated with differentiation, invasion depth, TNM stage and poor prognosis. NNT-AS1 downregulation significantly inhibited the proliferation, migration and invasion of CCA cells, while overexpression of NNT-AS1 promoted the invasion and survival of cells in vitro and in vivo. These studies also demonstrated that NNT-AS1 binds to miR-142-5p as a ceRNA, and the expression of miR-142-5p is negatively correlated with the expression of NNT-AS1 in CCA. These results suggest that NNT-AS1 plays a key role in the progression of CCA and is a potential therapeutic target for CCA. Multivariate analysis $(92,94)$ indicated that NNT-AS1 may be a new and effective risk biomarker. Several studies have suggested that upregulated NNT-AS1 could be used as an independent negative prognostic factor for cancer. For example, NNT-AS1 is increased in human osteosarcoma, cervical cancer, colorectal cancer, breast cancer, liver cancer and ovarian cancer (95). In addition, Hua et al (93) indicated that NNT-AS1 increased cell proliferation and invasion by activating the $\mathrm{Wnt} / \beta$-catenin pathway in cervical cancer. Liang et al (82) found that NNT-AS1 could accelerate the migration and invasion of cells in CCA and bound to miR-142-3p, thereby acting as a sponge.

SNHG1. A study by Yu et al (96) found that the expression of lncRNA SNHG1 showed strong upregulation in CCA tissues, and SNHG1 downregulation significantly inhibited cell growth in vivo and in vitro. SNHG1 also exhibited cancer-promoting properties in different types of tumours (96). There is evidence to show that SNHG1 interacts with EZH2, which is thought to be a histone-methylated modification complex in the nucleus that regulates various target genes. CDKN1A is one of the genes regulated by SNHG1, as shown by RNA sequencing (RNA-seq), and acts as a tumour suppressor gene in different types of cancer $(97,98)$. In addition, hypermethylation of the CDKN1A promoter region has been reported to contribute to CDKN1A transcriptional inactivation in breast cancer (99). SNHG1 binds to EZH2 to inhibit the expression of target genes, including CDKN1A, in CCA (89). Through epigenetic regulation of CDKN1A transcription in the nucleus, SNHG1 promotes the malignancy of CCA and the survival and metastasis of CCA cells (100).

PVT1. Following PVT1 knockdown, an analysis of RNA sequencing results on the basis of gene ontology revealed that this genetic change was strongly associated with proliferation and migration (101). Another study (102) found that PVT1 binds to EZH2 to form a histone-methylated modification complex in the nucleus, thereby potentially regulating various genes in CCA (103). DNA methylation in the promoter region of ANGPTL4 has been confirmed to lead to the inactivation of ANGPTL4 transcription (104). A study showed that PVT1-regulated histone methylation (H3K27me3) promoted a reduction in ANGPTL4 expression in CCA cell lines, and that PVT1 bound to EZH2 in the nucleus and mediated the epigenetic silencing of ANGPTL4 (101). Through this mechanism, PVT1 regulated the transcription of ANGPTL4 to promote cell survival and CCA metastasis, thus enhancing the malignancy of CCA (101). These findings indicate that PVT1, as a key IncRNA, may be crucial in the diagnosis, treatment and prognosis of CCA.

AL136359.1. The lncRNA AL136359.1 plays an important role in CCA. A study has shown that AL136359.1 expression leads to significant increases in the mRNA and protein levels of aldosterone reductase 1B10 (AKR1B10), and when the AKR1B10 gene was highly expressed, the protein levels of MMP-2, vimentin, CDK4 and Cyclin Dl were significantly reduced (105). In another study, IncRNA AL136359.1 was significantly decreased in CCA tissues and cell lines, and the high expression of AL136359.1 significantly promoted the expression of the AKRIBIO gene and further inhibited the proliferation and invasion of CCA cells (106).

Colon cancer-related transcript 2 (CCAT2). CCAT2 is a lncRNA that maps to the genomic region of 8q24. This lncRNA was first identified from microsatellite stable colorectal cancer and was shown to regulate the metastasis and progression of colon cancer and chromosomal instability (106). CCAT2 
can reduce $\mathrm{E}$-cadherin and increase $\mathrm{ZEB} 2$, vimentin and $\mathrm{N}$-cadherin expression, thus stimulating EMT (107). A study has shown that CCAT2 is upregulated in CCA tissues and cell lines, and the transcription level of CCAT2 is upregulated 1.39-3.20-fold in CCA tissues and cell lines compared with human intrahepatic bile duct epithelial cells (107). In vitro experiments have confirmed that CCAT2 silencing can significantly inhibit cell growth and increase cell apoptosis in CCA cells (106). Caspase-3 and -9 may play an important role in mediating the apoptosis induced by downregulation of CCAT2. Inhibition of CCAT2 expression can inhibit metastatic properties, reverse EMT, increase E-cadherin expression and decrease vimentin expression in CCA cells (106).

\section{Contribution of next-generation sequencing (NGS) to ncRNAs}

At present, most quantitative studies of ncRNA rely on RT-qPCR, in situ hybridization or microarray techniques. These methods have both advantages and limitations. NGS offers researchers a powerful tool for detecting RNA molecules in biological samples. In addition, the length of the protocol, sequencing time and expense are falling, making NGS an ideal tool for studying biomarkers (108). The advantages of NGS include the following: i) Species- or transcript-specific probes are not required. ii) NGS shows increased specificity and sensitivity for a wide range of applications. iii) The high coverage depth of sequencing helps detect rare or single-cell transcripts and identify weakly expressed genes.iv) NGS technology is able to detect multiple splice sites and novel isoforms. v) NGS technology is able to perform de novo analysis of a sample without a reference genome (108-110).

The operational process of NGS in ncRNA can be summarized in the following aspects: i) Library preparation or sample processing; ii) sequencing; iii) initial quality and raw data analyses; and iv) variant calling and data interpretation. This last step is dependent on the specific application (110).

\section{Conclusions}

The prognosis of carcinoma of the bile tract is poor, and it presents early and systemic metastasis lymph node involvement. Currently, iCCA lacks effective drug and chemotherapy regimens, and surgical resection is the most effective method to treat this malignancy. However, due to its specific anatomical site, hidden onset of disease and the lack of effective early diagnostic markers, patients with iCCA are often in the late stage of disease when they are diagnosed, and have lost the opportunity for radical surgery. CCA carcinogenesis is the result of various oncogenes, tumour suppressor genes and associated molecular disorders. Elucidation of the molecular mechanisms may help to identify effective therapeutic targets and biomarkers. Therefore, ncRNAs have gradually become an important topic of research. In this review, the biological characteristics of different ncRNAs, such as miRNAs, circRNAs and IncRNAs, are introduced, as well as their roles and mechanisms in CCA, and the clinical applications of relevant ncRNAs in CCA. An improved understanding of CCA biology has revealed the key role of ncRNAs in influencing CCA initiation, progression and therapeutic tolerance. Under these conditions, ncRNAs are being further studied as promising tumour biomarkers to be incorporated into clinical management and improve the prognosis of CCA patients. The initial results are encouraging; however, further studies are required to confirm their reliability and clinical reproducibility.

\section{Acknowledgements}

Not applicable.

\section{Funding}

No funding was received.

\section{Availability data and materials}

Not applicable.

\section{Authors' contributions}

YL and YZ conceived the study. YL, ZW, KZ and GZ conducted the literature search. YL, ZW, KZ and GZ wrote and prepared the original draft of the manuscript. All authors participated in the writing and reviewing of the article. YL, YZ and $\mathrm{SH}$ edited the article. All authors have read and approved the final manuscript.

\section{Ethics approval and consent to participate}

Not applicable.

\section{Patient consent for publication}

Not applicable.

\section{Competing interests}

The authors declare that they have no competing interests.

\section{References}

1. Blechacz B: Cholangiocarcinoma: Current Knowledge and New Developments. Gut Liver 11: 13-26, 2017.

2. Rizvi S, Khan SA, Hallemeier CL, Kelley RK and Gores GJ: Cholangiocarcinoma - evolving concepts and therapeutic strategies. Nat Rev Clin Oncol 15: 95-111, 2018.

3. Lv Y and Huang S: Role of non-coding RNA in pancreatic cancer. Oncol Lett 18: 3963-3973, 2019.

4. Wang KC and Chang HY: Molecular mechanisms of long noncoding RNAs. Mol Cell 43: 904-914, 2011.

5. Ponting CP, Oliver PL and Reik W: Evolution and functions of long noncoding RNAs. Cell 136: 629-641, 2009.

6. Wang Z, Yang B, Zhang M, Guo W, Wu Z, Wang Y, Jia L, Li S, Xie W, Yang D, et al; Cancer Genome Atlas Research Network: LncRNA epigenetic landscape analysis identifies EPIC1 as an oncogenic lncRNA that interacts with MYC and promotes cell cycle progression in cancer. Cancer Cell 33: 706-720.e9, 2018.

7. Han D, Gao X, Wang M, Qiao Y, Xu Y, Yang J, Dong N, He J, Sun Q, Lv G, et al: Long noncoding RNA H19 indicates a poor prognosis of colorectal cancer and promotes tumor growth by recruiting and binding to eIF4A3. Oncotarget 7: 22159-22173, 2016.

8. Lee RC, Feinbaum RL and Ambros V: The C. elegans heterochronic gene lin-4 encodes small RNAs with antisense complementarity to lin-14. Cell 75: 843-854, 1993.

9. Bushati N and Cohen SM: microRNA functions. Annu Rev Cell Dev Biol 23: 175-205, 2007. 
10. Lin S and Gregory RI: MicroRNA biogenesis pathways in cancer. Nat Rev Cancer 15: 321-333, 2015.

11. Pandey P, Srivastava PK and Pandey SP: Prediction of Plant miRNA Targets. Methods Mol Biol 1932: 99-107, 2019.

12. Borges F and Martienssen RA: The expanding world of small RNAs in plants. Nat Rev Mol Cell Biol 16: 727-741, 2015.

13. Ushijima K, Yamada Y, Yano T and Tashiro M: An electrosurgical burn possibly caused by radio-frequency leakage current through a stainless forceps. Masui 49: 909-912, 2000 (In Japanese).

14. Piontek K and Selaru FM: MicroRNAs in the biology and diagnosis of cholangiocarcinoma. Semin Liver Dis 35: 55-62, 2015.

15. Nakaoka T, Saito Y and Saito H: Aberrant DNA Methylation as a Biomarker and a Therapeutic Target of Cholangiocarcinoma. Int J Mol Sci 18: 18, 2017

16. Plieskatt J, Rinaldi G, Feng Y, Peng J, Easley S, Jia X, Potriquet J, Pairojkul C, Bhudhisawasdi V, Sripa B, et al: A microRNA profile associated with Opisthorchis viverrini-induced cholangiocarcinoma in tissue and plasma. BMC Cancer 15: 309, 2015 .

17. Petrache Voicu SN, Dinu D, Sima C, Hermenean A, Ardelean A, Codrici E, Stan MS, Zărnescu O and Dinischiotu A: Silica Nanoparticles Induce Oxidative Stress and Autophagy but Not Apoptosis in the MRC-5 Cell Line. Int J Mol Sci 16: 29398-29416, 2015.

18. Zhu H, Han C, Lu D and Wu T: miR-17-92 cluster promotes cholangiocarcinoma growth: Evidence for PTEN as downstream target and IL-6/Stat3 as upstream activator. Am J Pathol 184: $2828-2839,2014$

19. Hu C, Huang F, Deng G, Nie W, Huang W and Zeng X: miR-31 promotes oncogenesis in intrahepatic cholangiocarcinoma cells via the direct suppression of RASA1. Exp Ther Med 6: $1265-1270,2013$

20. Li J, Tian F, Li D, Chen J, Jiang P, Zheng S, Li X and Wang S: miR-605 represses PSMD10/Gankyrin and inhibits intrahepatic cholangiocarcinoma cell progression. FEBS Lett 588: 3491-3500, 2014.

21. Cheng Q, Feng F, Zhu L, Zheng Y, Luo X, Liu C, Yi B and Jiang X: Circulating miR-106a is a Novel Prognostic and Lymph Node Metastasis Indicator for Cholangiocarcinoma. Sci Rep 5: 16103, 2015

22. Patel T: Extracellular vesicle noncoding RNA: New players in the diagnosis and pathogenesis of cholangiocarcinoma. Hepatology 60: 782-784, 2014.

23. Canu V, Sacconi A, Lorenzon L, Biagioni F, Lo Sardo F, Diodoro MG, Muti P, Garofalo A, Strano S, D'Errico A, et al: miR-204 down-regulation elicited perturbation of a gene target signature common to human cholangiocarcinoma and gastric cancer. Oncotarget 8: 29540-29557, 2017.

24. Meng F, Henson R, Lang M, Wehbe H, Maheshwari S, Mendell JT, Jiang J, Schmittgen TD and Patel T: Involvement of human micro-RNA in growth and response to chemotherapy in human cholangiocarcinoma cell lines. Gastroenterology 130 : 2113-2129, 2006

25. Chen L, Yan HX, Yang W, Hu L, Yu LX, Liu Q, Li L, Huang DD, Ding J, Shen F, et al: The role of microRNA expression pattern in human intrahepatic cholangiocarcinoma. J Hepatol 50: 358-369, 2009.

26. Yang G, Zhang R, Chen X, Mu Y, Ai J, Shi C, Liu Y, Shi C, Sun L, Rainov NG, et al: miR-106a inhibits glioma cell growth by targeting E2F1 independent of p53 status. J Mol Med (Berl) 89: $1037-1050,2011$

27. Okamoto K, Miyoshi K and Murawaki Y: miR-29b, miR-205 and miR-221 enhance chemosensitivity to gemcitabine in $\mathrm{HuH} 28$ human cholangiocarcinoma cells. PLoS One 8: e77623, 2013.

28. Chen Y, Gao W, Luo J, Tian R, Sun H and Zou S: Methyl-CpG binding protein MBD2 is implicated in methylation-mediated suppression of miR-373 in hilar cholangiocarcinoma. Oncol Rep 25: 443-451, 2011.

29. An F, Yamanaka S, Allen S, Roberts LR, Gores GJ, Pawlik TM, Xie Q, Ishida M, Mezey E, Ferguson-Smith AC, et al: Silencing of miR-370 in human cholangiocarcinoma by allelic loss and interleukin-6 induced maternal to paternal epigenotype switch. PLoS One 7: e45606, 2012

30. Ngankeu A, Ranganathan P, Havelange V, Nicolet D, Volinia S, Powell BL, Kolitz JE, Uy GL, Stone RM, Kornblau SM, et al Discovery and functional implications of a miR-29b-1/miR-29a cluster polymorphism in acute myeloid leukemia. Oncotarget 9: $4354-4365,2017$
31. Mott JL, Kurita S, Cazanave SC, Bronk SF, Werneburg NW and Fernandez-Zapico ME: Transcriptional suppression of mir-29b-1/mir-29a promoter by c-Myc, hedgehog, and NF-kappaB. J Cell Biochem 110: 1155-1164, 2010.

32. Kwon H, Song K, Han C, Zhang J, Lu L, Chen W and Wu T: Epigenetic Silencing of miRNA-34a in Human Cholangiocarcinoma via EZH2 and DNA Methylation: Impact on Regulation of Notch Pathway. Am J Pathol 187: 2288-2299, 2017.

33. Li B, Han Q, Zhu Y, Yu Y, Wang J and Jiang X: Down-regulation of miR-214 contributes to intrahepatic cholangiocarcinoma metastasis by targeting Twist. FEBS J 279: 2393-2398, 2012.

34. Iwaki J, Kikuchi K, Mizuguchi Y, Kawahigashi Y, Yoshida H, Uchida E and Takizawa T: miR-376c down-regulation accelerates EGF-dependent migration by targeting GRB2 in the HuCCT1 human intrahepatic cholangiocarcinoma cell line. PLoS One 8: e69496, 2013

35. Peng F, Jiang J, Yu Y, Tian R, Guo X, Li X, Shen M, Xu M, Zhu F, Shi C, et al: Direct targeting of SUZ12/ROCK2 by miR-200b/c inhibits cholangiocarcinoma tumourigenesis and metastasis. $\mathrm{Br} \mathrm{J}$ Cancer 109: 3092-3104, 2013.

36. Yang R, Chen Y, Tang C, Li H, Wang B, Yan Q, Hu J and Zou S: MicroRNA-144 suppresses cholangiocarcinoma cell proliferation and invasion through targeting platelet activating factor acetylhydrolase isoform 1b. BMC Cancer 14: 917, 2014.

37. Zhang J, Han C, Zhu H, Song K and Wu T: miR-101 inhibits cholangiocarcinoma angiogenesis through targeting vascular endothelial growth factor (VEGF). Am J Pathol 182: 1629-1639, 2013.

38. Qiu YH, Wei YP, Shen NJ, Wang ZC, Kan T, Yu WL, Yi B and Zhang YJ: miR-204 inhibits epithelial to mesenchymal transition by targeting slug in intrahepatic cholangiocarcinoma cells. Cell Physiol Biochem 32: 1331-1341, 2013.

39. Kobayashi S, Werneburg NW, Bronk SF, Kaufmann SH and Gores GJ: Interleukin- 6 contributes to Mcl-1 up-regulation and TRAIL resistance via an Akt-signaling pathway in cholangiocarcinoma cells. Gastroenterology 128: 2054-2065, 2005.

40. Xiong B, Cheng Y, Ma L and Zhang C: miR-21 regulates biological behavior through the PTEN/PI-3 K/Akt signaling pathway in human colorectal cancer cells. Int J Oncol 42 : 219-228, 2013.

41. Selaru FM, Olaru AV, Kan T, David S, Cheng Y, Mori Y, Yang J, Paun B, Jin Z, Agarwal R, et al: MicroRNA-21 is overexpressed in human cholangiocarcinoma and regulates programmed cell death 4 and tissue inhibitor of metalloproteinase 3. Hepatology 49: 1595-1601, 2009.

42. Jiang Y, Goldberg ID and Shi YE: Complex roles of tissue inhibitors of metalloproteinases in cancer. Oncogene 21: 2245-2252, 2002

43. He Q, Cai L, Shuai L, Li D, Wang C, Liu Y, Li X, Li Z and Wang S: Ars2 is overexpressed in human cholangiocarcinomas and its depletion increases PTEN and PDCD 4 by decreasing microRNA-21. Mol Carcinog 52: 286-296, 2013.

44. Lu L, Byrnes K, Han C, Wang Y and Wu T: miR-21 targets 15-PGDH and promotes cholangiocarcinoma growth. Mol Cancer Res 12: 890-900, 2014

45. Triboulet R, Pirouz M and Gregory RI: A Single Let-7 MicroRNA Bypasses LIN28-Mediated Repression. Cell Rep 13: 260-266, 2015.

46. Au SL, Wong CC, Lee JM, Fan DN, Tsang FH, Ng IO and Wong CM: Enhancer of zeste homolog 2 epigenetically silences multiple tumor suppressor microRNAs to promote liver cancer metastasis. Hepatology 56: 622-631, 2012

47. Xie Y, Zhang H, Guo XJ, Feng YC, He RZ, Li X, Yu S, Zhao Y, Shen M, Zhu F, et al: Let-7c inhibits cholangiocarcinoma growth but promotes tumor cell invasion and growth at extrahepatic sites. Cell Death Dis 9: 249, 2018.

48. LinKY, YeH, Han BW, Wang WT, WeiPP,HeB, LiXJ and Chen YQ: Genome-wide screen identified let-7c/miR-99a/miR-125b regulating tumor progression and stem-like properties in cholangiocarcinoma. Oncogene 35: 3376-3386, 2016.

49. Meng F, Henson R, Wehbe-Janek H, Smith H, Ueno Y and Patel T: The MicroRNA let-7a modulates interleukin-6-dependent STAT-3 survival signaling in malignant human cholangiocytes. J Biol Chem 282: 8256-8264, 2007.

50. Gregory PA, Bert AG, Paterson EL, Barry SC, Tsykin A, Farshid G, Vadas MA, Khew-Goodall Y and Goodall GJ: The miR-200 family and miR-205 regulate epithelial to mesenchymal transition by targeting ZEB1 and SIP1. Nat Cell Biol 10: 593-601, 2008 . 
51. Korpal M,Lee ES,Hu G and Kang Y: The miR-200 family inhibits epithelial-mesenchymal transition and cancer cell migration by direct targeting of E-cadherin transcriptional repressors ZEB1 and ZEB2. J Biol Chem 283: 14910-14914, 2008.

52. Greene J, Baird AM, Brady L, Lim M, Gray SG, McDermott R and Finn SP: Circular RNAs: Biogenesis, Function and Role in Human Diseases. Front Mol Biosci 4: 38, 2017.

53. Zhang Z, Xie Q, He D, Ling Y, Li Y, Li J and Zhang H: Circular RNA: new star, new hope in cancer. BMC Cancer 18: 834, 2018.

54. Werfel S, Nothjunge S, Schwarzmayr T, Strom TM, Meitinger T and Engelhardt S: Characterization of circular RNAs in human, mouse and rat hearts. J Mol Cell Cardiol 98: 103-107, 2016.

55. Xiong Y, Zhang J and Song C: CircRNA ZNF609 functions as a competitive endogenous RNA to regulate FOXP4 expression by sponging miR-138-5p in renal carcinoma. J Cell Physiol 234: 10646-10654, 2019.

56. Xu Y, Yao Y, Leng K, Ji D, Qu L, Liu Y and Cui Y: Increased Expression of Circular RNA circ 0005230 Indicates Dismal Prognosis in Breast Cancer and Regulates Cell Proliferation and Invasion via miR-618/CBX8 Signal Pathway. Cell Physiol Biochem 51: 1710-1722, 2018.

57. Xu Y, Yao Y, Liu Y, Wang Z, Hu Z, Su Z, Li C, Wang H, Jiang X, Kang P, et al: Elevation of circular RNA circ_0005230 facilitates cell growth and metastasis via sponging miR-1238 and miR-1299 in cholangiocarcinoma. Aging (Albany NY) 11: 1907-1917, 2019

58. Shi X, Zhan L, Xiao C, Lei Z, Yang H, Wang L, Zhao J and Zhang HT: miR-1238 inhibits cell proliferation by targeting LHX2 in non-small cell lung cancer. Oncotarget 6: 19043-19054, 2015.

59. Jiang XM, Li ZL, Li JL, Xu Y, Leng KM, Cui YF and Sun DJ: A novel prognostic biomarker for cholangiocarcinoma: circRNA Cdrlas. Eur Rev Med Pharmacol Sci 22: 365-371, 2018.

60. Xu Y, Yao Y, Zhong X, Leng K, Qin W, Qu L, Cui Y and Jiang X: Downregulated circular RNA hsa_circ_0001649 regulates proliferation, migration and invasion in cholangiocarcinoma cells. Biochem Biophys Res Commun 496: 455-461, 2018.

61. Wang S, Hu Y,Lv X,Li B, Gu D, Li Y,Sun Y and Su Y: Circ-0000284 arouses malignant phenotype of cholangiocarcinoma cells and regulates the biological functions of peripheral cells through cellular communication. Clin Sci (Lond) 133: 1935-1953, 2019.

62. Sun M and Kraus WL: From discovery to function: The expanding roles of long noncoding RNAs in physiology and disease. Endocr Rev 36: 25-64, 2015.

63. Chen J, Miao Z, Xue B, Shan Y, Weng G and Shen B: Long Non-coding RNAs in Urologic Malignancies: Functional Roles and Clinical Translation. J Cancer 7: 1842-1855, 2016.

64. Wang J, Xie H, Ling Q, Lu D, Lv Z, Zhuang R, Liu Z, Wei X, Zhou L, Xu X, et al: Coding-noncoding gene expression in intrahepatic cholangiocarcinoma. Transl Res 168: 107-121, 2016.

65. Hao S, Yao L, Huang J, He H, Yang F, Di Y, Jin C and Fu D. Genome-Wide Analysis Identified a Number of Dysregulated Long Noncoding RNA (lncRNA) in Human Pancreatic Ductal Adenocarcinoma. Technol Cancer Res Treat 17: 1533034617748429,2018

66. Yao Y, Sun Y, Jiang Y, Qu L and Xu Y: Enhanced expression of lncRNA TP73-AS1 predicts adverse phenotypes for cholangiocarcinoma and exerts oncogenic properties in vitro and in vivo. Biomed Pharmacother 106: 260-266, 2018.

67. Li Y, Cai Q, Li W, Feng F and Yang L: Long non-coding RNA EPIC1 promotes cholangiocarcinoma cell growth. Biochem Biophys Res Commun 504: 654-659, 2018.

68. Xu Y, Wang Z, Jiang X and Cui Y: Overexpression of long noncoding RNA H19 indicates a poor prognosis for cholangiocarcinoma and promotes cell migration and invasion by affecting epithelial-mesenchymal transition. Biomed Pharmacother 92: $17-23,2017$

69. Wang WT, Ye H, Wei PP, Han BW, He B, Chen ZH and Chen YQ: LncRNAs H19 and HULC, activated by oxidative stress, promote cell migration and invasion in cholangiocarcinoma through a ceRNA manner. J Hematol Oncol 9: 117, 2016

70. Zhang S, Xiao J, Chai Y, Du YY, Liu Z, Huang K, Zhou X and Zhou W: LncRNA-CCAT1 Promotes Migration, Invasion, and EMT in Intrahepatic Cholangiocarcinoma Through Suppressing miR-152. Dig Dis Sci 62: 3050-3058, 2017.

71. Ma F, Wang SH, Cai Q, Zhang MD, Yang Y and Ding J: Overexpression of LncRNA AFAP1-AS1 predicts poor prognosis and promotes cells proliferation and invasion in gallbladder cancer. Biomed Pharmacother 84: 1249-1255, 2016.

72. Zhang C, Li JY, Tian FZ, Zhao G, Hu H, Ma YF and Yang YL: Long Noncoding RNA NEAT1 Promotes Growth and Metastasis of Cholangiocarcinoma Cells. Oncol Res 26: 879-888, 2018.
73. Parasramka M, Yan IK, Wang X, Nguyen P, Matsuda A, Maji S, Foye C, Asmann Y and Patel T: BAP1 dependent expression of long non-coding RNA NEAT-1 contributes to sensitivity to gemcitabine in cholangiocarcinoma. Mol Cancer 16: 22, 2017.

74. Ma SL, Li AJ, Hu ZY, Shang FS and Wu MC: Co expression of the carbamoyl phosphate synthase 1 gene and its long non coding RNA correlates with poor prognosis of patients with intrahepatic cholangiocarcinoma. Mol Med Rep 12: 7915-7926, 2015.

75. Wang C, Mao ZP, Wang L, Wu GH, Zhang FH, Wang DY and Shi JL: Long non-coding RNA MALAT1 promotes cholangiocarcinoma cell proliferation and invasion by activating PI3K/Akt pathway. Neoplasma 64: 725-731, 2017.

76. Shi X, Sun M, Liu H, Yao Y and Song Y: Long non-coding RNAs: A new frontier in the study of human diseases. Cancer Lett 339: 159-166, 2013.

77. Tan X, Huang Z and Li X: Long Non-Coding RNA MALAT1 Interacts With miR-204 to Modulate Human Hilar Cholangiocarcinoma Proliferation, Migration, and Invasion by Targeting CXCR4. J Cell Biochem 118: 3643-3653, 2017.

78. Qin X, Lu M, Zhou Y, Li G and Liu Z: LncRNA FENDRR represses proliferation, migration and invasion through suppression of survivin in cholangiocarcinoma cells. Cell Cycle 18: 889-897, 2019.

79. Zhang X, Zhou Y, Mehta KR, Danila DC, Scolavino S, Johnson SR and Klibanski A: A pituitary-derived MEG3 isoform functions as a growth suppressor in tumor cells. J Clin Endocrinol Metab 88: 5119-5126, 2003.

80. Xia Y, He Z, Liu B, Wang P and Chen Y: Downregulation of Meg3 enhances cisplatin resistance of lung cancer cells through activation of the WNT/ $\beta$-catenin signaling pathway. Mol Med Rep 12: 4530-4537, 2015.

81. SribenjaS,NatthasirikulN, VaeteewoottacharnK,SawanyawisuthK, Wongkham C, Jearanaikoon P and Wongkham S: Thymosin $\beta 10$ as a predictive biomarker of response to 5-fluorouracil chemotherapy in cholangiocarcinoma. Ann Hepatol 15: 577-585, 2016.

82. Liang Z, Zhu B, Meng D, Shen X, Li X, Wang Z and Li L: Down-regulation of IncRNA-NEF indicates poor prognosis in intrahepatic cholangiocarcinoma. Biosci Rep 39: 39, 2019.

83. Hu X, Tan Z, Yang Y and Yang P: Long non-coding RNA MIR22HG inhibits cell proliferation and migration in cholangiocarcinoma by negatively regulating the $\mathrm{Wnt} / \beta$-catenin signaling pathway. J Gene Med 21: e3085, 2019.

84. Luo M, Li Z, Wang W, Zeng Y, Liu Z and Qiu J: Long non-coding RNA H19 increases bladder cancer metastasis by associating with EZH2 and inhibiting E-cadherin expression. Cancer Lett 333: 213-221, 2013

85. Monnier P, Martinet C, Pontis J, Stancheva I, Ait-Si-Ali S and Dandolo L: H19 lncRNA controls gene expression of the Imprinted Gene Network by recruiting MBD1. Proc Natl Acad Sci USA 110: 20693-20698, 2013.

86. Du Y,Kong G, You X,Zhang S,Zhang T, Gao Y, Ye L and Zhang X: Elevation of highly up-regulated in liver cancer (HULC) by hepatitis $\mathrm{B}$ virus $\mathrm{X}$ protein promotes hepatoma cell proliferation via down-regulating p18. J Biol Chem 287: 26302-26311, 2012.

87. King CE, Cuatrecasas M, Castells A, Sepulveda AR, Lee JS and Rustgi AK: LIN28B promotes colon cancer progression and metastasis. Cancer Res 71: 4260-4268, 2011.

88. Viswanathan SR and Daley GQ: Lin28: A microRNA regulator with a macro role. Cell 140: 445-449, 2010.

89. Cao MX, Jiang YP, Tang YL and Liang XH: The crosstalk between lncRNA and microRNA in cancer metastasis: Orchestrating the epithelial-mesenchymal plasticity. Oncotarget 8: 12472-12483, 2017

90. Jia P, Cai H, Liu X, Chen J, Ma J, Wang P, Liu Y, Zheng J and Xue Y: Long non-coding RNA H19 regulates glioma angiogenesis and the biological behavior of glioma-associated endothelial cells by inhibiting microRNA-29a. Cancer Lett 381: 359-369, 2016.

91. Gu Y, Li C, Xiao L, Li J, Pei H, Xu D, Jiang Y, Zhang X, Zhang L, Li K, et al: High expression of long non-coding RNA NNT-AS1 facilitates progression of cholangiocarcinoma through promoting epithelial-mesenchymal transition. Am J Transl Res 11: 5438-5456, 2019.

92. Wang X, Ren M, Li Y, Hu J, Lu G, Ma W, Guo D, Lu X and He S: Long noncoding RNA NNT-AS1 promotes gastric cancer proliferation and invasion by regulating microRNA-363 expression. $\mathrm{J}$ Cell Biochem 120: 5704-5712, 2019.

93. Hua F, Liu S, Zhu L, Ma N, Jiang S and Yang J: Highly expressed long non-coding RNA NNT-AS1 promotes cell proliferation and invasion through $\mathrm{Wnt} / \beta$-catenin signaling pathway in cervical cancer. Biomed Pharmacother 92: 1128-1134, 2017. 
94. Huang Y, Shi J and Xu Y: Long non-coding RNA NNT-AS1 contributes to cell proliferation, metastasis and apoptosis in human ovarian cancer. Oncol Lett 15: 9264-9270, 2018.

95. Merry CR, Forrest ME, Sabers JN, Beard L, Gao XH, Hatzoglou M, Jackson MW, Wang Z, Markowitz SD and Khalil AM: DNMT1-associated long non-coding RNAs regulate global gene expression and DNA methylation in colon cancer. Hum Mol Genet 24: 6240-6253, 2015.

96. Yu Y, Zhang M, Wang N, Li Q, Yang J, Yan S, He X, Ji G and Miao L: Epigenetic silencing of tumor suppressor gene CDKN1A by oncogenic long non-coding RNA SNHG1 in cholangiocarcinoma.Cell Death Dis 9: 746, 2018.

97. Jalili A, Wagner C, Pashenkov M, Pathria G, Mertz KD, Widlund HR, Lupien M, Brunet JP, Golub TR, Stingl G, et al: Dual suppression of the cyclin-dependent kinase inhibitors CDKN2C and CDKN1A in human melanoma. J Natl Cancer Inst 104: 1673-1679, 2012.

98. Guo H, Xu Y and Fu Q: Curcumin inhibits growth of prostate carcinoma via miR-208-mediated CDKN1A activation. Tumour Biol 36: 8511-8517, 2015

99. Askari M, Sobti RC, Nikbakht M and Sharma SC: Aberrant promoter hypermethylation of p21 (WAF1/CIP1) gene and its impact on expression and role of polymorphism in the risk of breast cancer. Mol Cell Biochem 382: 19-26, 2013.

100. Yu Y, Zhang M, Liu J, Xu B, Yang J, Wang N, Yan S, Wang F, He X, Ji G, et al: Long Non-coding RNA PVT1 Promotes Cell Proliferation and Migration by Silencing ANGPTL4 Expression in Cholangiocarcinoma. Mol Ther Nucleic Acids 13: 503-513, 2018.

101. Kong R, Zhang EB, Yin DD, You LH, Xu TP, Chen WM, Xia R Wan L, Sun M, Wang ZX, et al: Long noncoding RNA PVT1 indicates a poor prognosis of gastric cancer and promotes cell proliferation through epigenetically regulating $\mathrm{p} 15$ and $\mathrm{p} 16 . \mathrm{Mol}$ Cancer 14: 82, 2015.

102. Tsai MC, Manor O, Wan Y, Mosammaparast N, Wang JK, Lan F, Shi Y, Segal E and Chang HY: Long noncoding RNA as modular scaffold of histone modification complexes. Science 329: 689-693, 2010.

103. Okochi-Takada E, Hattori N, Tsukamoto T, Miyamoto K, Ando T, Ito S, Yamamura Y, Wakabayashi M, Nobeyama Y and Ushijima T: ANGPTL4 is a secreted tumor suppressor that inhibits angiogenesis. Oncogene 33: 2273-2278, 2014

104. Taskoparan B, Seza EG, Demirkol S, Tuncer S, Stefek M, Gure AO and Banerjee S: Opposing roles of the aldo-keto reductases AKR1B1 and AKR1B10 in colorectal cancer. Cell Oncol (Dordr) 40: 563-578, 2017.

105. Sinreih M, Stupar S, Cemažar L, Verdenik I, Frković Grazio S, Smrkolj Š and Rižner TL: STAR and AKR1B10 are down-regulated in high-grade endometrial cancer. J Steroid Biochem Mol Biol 171: 43-53, 2017

106.Xu Y, Yao Y, Qin W, Zhong X, Jiang X and Cui Y: Long non-coding RNA CCAT2 promotes cholangiocarcinoma cells migration and invasion by induction of epithelial-to-mesenchymal transition. Biomed Pharmacother 99: 121-127, 2018.

107. Bai JG, Tang RF, Shang JF, Qi S, Yu GD and Sun C: Upregulation of long non coding RNA CCAT2 indicates a poor prognosis and promotes proliferation and metastasis in intrahepatic cholangiocarcinoma. Mol Med Rep 17: 5328-5335, 2018.

108. Le Gallo M, Lozy F and Bell DW: Next-Generation Sequencing. Adv Exp Med Biol 943: 119-148, 2017.

109.Levy SE and Myers RM: Advancements in Next-Generation Sequencing. Annu Rev Genomics Hum Genet 17: 95-115, 2016.

110. Slatko BE, Gardner AF and Ausubel FM: Overview of Next-Generation Sequencing Technologies. Curr Protoc Mol Biol 122: e59, 2018

111. Zhang J, Han C and Wu T: MicroRNA-26a promotes cholangiocarcinoma growth by activating $\beta$-catenin. Gastroenterology 143 : 246-56.e8, 2012.

112. Namwat $\mathrm{N}$, Chusorn P, Loilome W, Techasen A, Puetkasichonpasutha J, Pairojkul C, Khuntikeo N and Yongvanit P: Expression profiles of oncomir miR-21 and tumor suppressor let-7a in the progression of opisthorchiasis-associated cholangiocarcinoma. Asian Pac J Cancer Prev 13 (Suppl): 65-69, 2012.

113. Meng F, Henson R, Wehbe-Janek H, Ghoshal K, Jacob ST and Patel T: MicroRNA-21 regulates expression of the PTEN tumor suppressor gene in human hepatocellular cancer. Gastroenterology 133: 647-658, 2007.
114. Razumilava N, Bronk SF, Smoot RL, Fingas CD, Werneburg NW, Roberts LR and Mott JL: miR-25 targets TNF-related apoptosis inducing ligand (TRAIL) death receptor-4 and promotes apoptosis resistance in cholangiocarcinoma. Hepatology 55: 465-475, 2012

115. Khapre RV, Samsa WE and Kondratov RV: Circadian regulation of cell cycle: Molecular connections between aging and the circadian clock. Ann Med 42: 404-415, 2010.

116. Yang H, Li TW, Peng J, Tang X, Ko KS, Xia M and Aller MA: A mouse model of cholestasis-associated cholangiocarcinoma and transcription factors involved in progression. Gastroenterology 141: 378-388.e3884, 2011.

117. Li Q, Xia X, Ji J, Ma J, Tao L, Mo L and Chen W: miR-199a-3p enhances cisplatin sensitivity of cholangiocarcinoma cells by inhibiting mTOR signaling pathway and expression of MDR1. Oncotarget 8: 33621-33630, 2017.

118. Zhong XY, Yu JH, Zhang WG, Wang ZD, Dong Q, Tai S, Cui YF and Li H: MicroRNA-421 functions as an oncogenic miRNA in biliary tract cancer through down-regulating farnesoid $\mathrm{X}$ receptor expression. Gene 493: 44-51, 2012.

119. Olaru AV, Ghiaur G, Yamanaka S, Luvsanjav D, An F, Popescu I, Alexandrescu S, Allen S, Pawlik TM, Torbenson M, et al: MicroRNA down-regulated in human cholangiocarcinoma control cell cycle through multiple targets involved in the G1/S checkpoint. Hepatology 54: 2089-2098, 2011.

120. Cermakian N and Sassone-Corsi P: Multilevel regulation of the circadian clock. Nat Rev Mol Cell Biol 1: 59-67, 2000.

121. Han Y, Meng F, Venter J, Wu N, Wan Y, Standeford H, Francis H, Meininger C, Greene J Jr, Trzeciakowski JP, et al: miR-34a-dependent overexpression of Per1 decreases cholangiocarcinoma growth. J Hepatol 64: 1295-1304, 2016.

122. Qiao P, Li G, Bi W, Yang L, Yao L and Wu D: microRNA-34a inhibits epithelial mesenchymal transition in human cholangiocarcinoma by targeting Smad4 through transforming growth factor-beta/Smad pathway. BMC Cancer 15: 469, 2015.

123. Palumbo T, Poultsides GA, Kouraklis G, Liakakos T, Drakaki A, Peros G, Hatziapostolou M and Iliopoulos D: A functional microRNA library screen reveals miR-410 as a novel anti-apoptotic regulator of cholangiocarcinoma. BMC Cancer 16: 353, 2016.

124. Braconi C, Huang N and Patel T: MicroRNA-dependent regulation of DNA methyltransferase-1 and tumor suppressor gene expression by interleukin- 6 in human malignant cholangiocytes. Hepatology 51: 881-890, 2010.

125. Chen Y, Luo J, Tian R, Sun H and Zou S: miR-373 negatively regulates methyl-CpG-binding domain protein 2 (MBD2) in hilar cholangiocarcinoma. Dig Dis Sci 56: 1693-1701, 2011.

126.Zeng B, Ye H, Chen J, Cheng D, Cai C, Chen G, Chen X, Xin H, Tang C and Zeng J: LncRNA TUG1 sponges miR-145 to promote cancer progression and regulate glutamine metabolism via Sirt3/GDH axis. Oncotarget 8: 113650-113661, 2017.

127. Zhang F, Wan M, Xu Y, Li Z, Leng K, Kang P, Cui Y and Jiang X: Long noncoding RNA PCAT1 regulates extrahepatic cholangiocarcinoma progression via the $\mathrm{Wnt} / \beta$-catenin-signaling pathway. Biomed Pharmacother 94: 55-62, 2017.

128. Kong L, Wu Q, Zhao L, Ye J, Li N and Yang H: Upregulated IncRNA-UCA1 contributes to metastasis of bile duct carcinoma through regulation of $\mathrm{miR}-122 / \mathrm{CLIC} 1$ and activation of the ERK/MAPK signaling pathway. Cell Cycle 18: 1212-1228, 2019.

129. Xu Y, Yao Y, Jiang X, Zhong X, Wang Z, Li C, Kang P, Leng K, Ji D, Li Z, et al: SP1-induced upregulation of lncRNA SPRY4-IT1 exerts oncogenic properties by scaffolding EZH2/LSD1/DNMT1 and sponging miR-101-3p in cholangiocarcinoma. J Exp Clin Cancer Res 37: 81, 2018.

130. Carotenuto P, Fassan M, Pandolfo R, Lampis A, Vicentini C, Cascione L, Paulus-Hock V, Boulter L, Guest R, Quagliata L, et al: Wnt signalling modulates transcribed-ultraconserved regions in hepatobiliary cancers. Gut 66: 1268-1277, 2017.

131. Zhang D, Li H, Xie J, Jiang D, Cao L, Yang X, Xue P and Jiang X: Long noncoding RNA LINC01296 promotes tumor growth and progression by sponging miR-5095 in human cholangiocarcinoma. Int J Oncol 52: 1777-1786, 2018. 